Money and price dynamics under the gold standard in the neoclassical theory of growth

\author{
Wei-Bin Zhang
}


Lecturas de Economía, 90 (enero-junio 2019), pp. 45-69

Wei-Bin Zhang

Money and price dynamics under the gold standard in the neoclassical theory of growth

\begin{abstract}
The purpose of this study is to determine money and price dynamics under the gold standard in the one-sector neoclassical growth model. To do this, a model is built upon a fen approaches in the literature on dynamic economic theory. In particular, the production sector is based on the Solow model, the gold standard and price dynamics are founded on Barro (1979), and money demand is influenced by the traditional money-in-the-utility-function setup. The model integrates the ideas of these approaches within a compact framework. Through simulations, it is shown that the economic system is characterized by a unique unstable steady state. Also, comparative dynamic analyses regarding changes in some parameters are conducted.
\end{abstract}

Keywords: gold standard, growth model, wealth accumulation, inflation.

JEL Classification: $041,042, E 21, G 11,038$.

Dinámica del dinero y los precios bajo el patrón oro en la teoría neoclásica del crecimiento

Resumen: El propósito de este estudio es determinar la dinámica del dinero y los precios bajo el patrón oro en un modelo de crecimiento neoclasico de un sector. Para esto, se construye un modelo utilizando algunas aproximaciones de la literatura sobre la teoría de la dinámica económica. En particular, el sector productivo se basa en el modelo de Solow, el patrón oro y la dinámica de los precios está fundamentada en Barro (1979) y la demanda de dinero está influenciada por el marco tradicional con dinero en la función de utilidad. El modelo integra las ideas de estas aproximaciones dentro de una estructura compacta. A través de simulaciones, se muestra que el sistema económico se caracteriza por un estado estacionario único e inestable. También se llevan a cabo análisis de dinámica comparativa respecto a cambios en algunos parámetros.

Palabras clave: patrón oro, modelo de crecimiento, acumulación de riqueza, inflación.

Clasificación JEL: O41, O42, E21, G11, O38.

Dynamique de la monnaie et des prix sous le régime de l'étalon-or dans la théorie néoclassique de la croissance

Résumé: L'objectif de cette étude est de déterminer la dynamique de la quantité de monnaie et des prix sous un régime de l'étalon-or dans un modèle de croissance néoclassique à un secteur. Pour cela, un modèle est construit à l'aide de quelques approximations de la littérature sur la théorie de la dynamique économique. En particulier, le secteur productif est basé sur le modèle de Solow, l'hypothèse de l'étalon-or et la dynamique des prix sont basés sur Barro (1979) et la demande de monnaie est influencée par le cadre traditionnel où la monnaie rentre dans la fonction d'utilité. Le modèle intègre les idées de ces différentes approches dans une seule structure compacte. Des simulations montrent que le système économique est caractérisé par un état stationnaire unique et instable. Des analyses dynamiques comparatives sont également effectuées à partir des modifications dans certains paramètres.

Mots-clés: étalon-or, modèle de croissance, accumulation de richesse, inflation.

Classification JEL: O41, O42, E21, G11, O38. 


\title{
Money and price dynamics under the gold standard in the neoclassical theory of growth
}

\author{
Wei-Bin Zhang (10a \\ -Introduction. -I. The basic model. -II. The dynamics and its properties. -III. Comparative \\ dynamic analysis through simulations. -Concluding Remarks. -Appendix: Proof of Lemma. \\ - References.
}

doi: 10.17533/udea.le.n90a02

Original manuscript received on 28 August 2017; final version accepted on 24 January 2018

\section{Introduction}

This study aims to examine dynamic interactions between wealth accumulation, gold distribution between monetary and non-monetary uses, and government policy under the gold standard. As far as the growth mechanism is concerned, the model of this study is developed within the framework of the neoclassical growth theory. The seminal paper in this field is due to Solow (1956). The theory is mainly concerned with endogenous physical capital or wealth accumulation (Burmeister \& Dobell, 1970; Azariadis, 1993; Barro \& Sala-i-Martin, 1995). We follow the Solow model in modeling economic production. We analyze household behavior using the approach proposed by Zhang (1993) and introduce gold based on Barro's (1979) approach.

Furthermore, this study aims to examine gold price dynamics within a neoclassical growth model under the gold standard. Dynamics of gold prices are well mentioned but not properly theoretically examined within a modern growth theory with endogenous wealth accumulation. There are many empirical studies on gold prices and the real rate of return on gold (Dubey,

a Wei-Bin Zhang: professor, Ritsumeikan Asia Pacific University, Japan.

E-mail: wbz1@apu. ac.jp. https://orcid.org/0000-0002-3012-304X

The author would like to acknowledge two anonymous referees for constructive comments and the editor for effective editorial work. 
Zhang: Money and price dynamics under the gold standard in the neoclassical theory...

Geanakoplos \& Shubik, 2003; Ranson, 2005; Dempster, 2009; and Seemuang \& Rompreert, 2013). Forces of supply and demand for gold are not like other commodities. On the supply side, the amount of gold stock changes very slowly. On the demand side, most of gold is used for jewelry, coin collections and central banks, with less than $10 \%$ used for industrial production (Thomas, 2015). This study follows some dynamic models on gold prices (Barro, 1979; Bordo \& Ellson, 1985; Dowd \& Sampson, 1993; Chappell \& Dowd, 1997). We deviate from previous studies mainly in that our model also takes account of both wealth accumulation and physical capital accumulation, something neglected in most of the preceding literature. As saving can be conducted by keeping gold and accumulating wealth, dynamics of gold prices should be closely related to physical capital accumulation and other variables. We study the dynamic interdependence between economic growth and gold prices. It should be noted that although the gold standard has been abandoned a century ago in terms of its use as a medium of exchange and the monetary use of gold is quite limited even since the end of World War I, our study is theoretically meaningful as it provides insights into possible relations between gold values and economic variables.

Many of the most intriguing and important questions in dynamic economic analysis involve money. It is generally agreed that modern analysis on the dynamic interaction between inflation and capital formation begins with Tobin's seminal contribution in 1965. Tobin (1965) deals with an isolated economy in which "outside money" competes with real capital in the portfolios of agents within the framework of the Solow model. In our approach, the money supply is based on Barro (1979), who pointed out that "It is frequently argued that the deflationist tendency of the gold standard can be countered by supplementing the world's gold stock with some form of paper gold. For example, the plans suggested by Keynes (1943), Triffin (1960, part II), and Mundell (1971, pp. I35-6) can be viewed in this context." (p. 21). This study introduces paper money under the gold standard into the neoclassical growth theory. Rather than assuming some demand function for money like in Barro's approach, we derive money demand from the optimal decision of households. We apply the money in the utility (MIU) function approach. This approach was used initially by Patinkin (1965) and Sidrauski (1967). In this 
approach, money is held because it yields some services and the way to model it is to enter real balances directly into the utility function (Zhang, 2009).

This study proceeds as follows. Section I introduces the basic model. Section II simulates it. Section III carries out comparative dynamic analyses regarding some parameters. The last section concludes.

\section{The basic model}

The model is built upon a few approaches in the literature on the theory of economic growth. In particular, the production sector is based on the Solow model, the gold standard and price dynamics are based on Barro (1979), and household behavior is based on Zhang (1993, 2009). The money demand in Zhang's approach is based on the traditional MIU model (Sidrauski, 1967). As in the Solow growth model, the economy has one sector producing a single commodity for consumption and investment. Capital depreciates at a constant exponential rate, $\delta_{k}$ which is independent of the manner of use. The technology of the production sector is characterized by constant returns to scale. All markets are perfectly competitive. Factors are inelastically supplied and the available factors are fully utilized at every moment. Saving is undertaken only by households. All earnings of firms are distributed in the form of payments to factors of production. Households own assets in the form of physical wealth and gold. They allocate their incomes to consumption and wealth accumulation. Population is homogeneous. Let $N$ stand for the fixed population.

\section{A. The production sector}

The production sector uses capital and labor as inputs. Let $K(t)$ stand for the capital stock at time $t$. We use $F(t)$ to represent the output level. The production function is

$$
F(t)=A K^{\alpha}(t) N^{\beta}, \alpha, \beta>0, \alpha+\beta=1,
$$

where $A, \alpha$ and $\beta$ are parameters. Markets are competitive; thus, labor and capital earn their marginal products, and firms earn zero profits. Let the rate 
Zhang: Money and price dynamics under the gold standard in the neoclassical theory...

of interest and the wage rate per unit of time be denoted, respectively, $r(t)$ and $w(t)$ For any individual firm, and are given at any point in time. The production sector chooses and to maximize profits. The optimality conditions are

$$
\begin{gathered}
r(t)+\delta_{k}=\frac{a p(t) F(t)}{K(t)}, \\
w(t)=\frac{\beta p(t) F(t)}{N},
\end{gathered}
$$

where $p(t)$ is the price of the commodity.

\section{B. Money supply}

Following Barro (1979), we now describe the money supply. Let $M(t)$ stand for the stock of money at time $t$. This stock is denominated in a nominal unit such as yen. This stock represents the liabilities of the central bank. Money takes the physical form of paper claims. As in Ricardo (1821), it is assumed that the bank is ready to buy or sell any amount of gold in exchange for money at the fixed (yen) price $p_{G}(t)$. Let $G_{b}(t)$ denote the stock of gold held by the central bank. As in Barro, total money supply is

$$
M^{s}(t) \frac{p_{G}(t) G_{b}(t)}{\theta}, 0<\theta \leq 1,
$$

where the parameter $\theta$ measures the gold backing of the monetary issuance.

\section{Households' choice between physical wealth and gold}

This study assumes that money is used only by households. ${ }^{1}$ The demand for money per household is denoted by $m(t)$. Aggregate demand for money is

It should be noted that Barro (1979) directly assumes that the demand for circulating medium is dependent on the price of commodities, the expected rate of inflation, and exogenous real income. Barro's way of assuming an exogenously real income makes his analysis much easier, but it does not provide any insight into economic growth and issues related to the choice between gold and other assets. Following contemporary monetary growth theory, we derive the money demand from utility maximization. 


$$
M^{d}(t)=m(t) N
$$

Gold can be sold and bought in free markets without any frictions and transaction costs. Gold use will not waste. Households can own money, gold and physical wealth. In order to model the cost of keeping and using gold, we assume that gold can be "rented" through markets for decoration. We consider that the gold that is owned by the representative household can be used either by the household for decoration or rented out to other households. The rent of gold is denoted by $R_{G}(t)$. Consider now an investor with one unit of money. He can either invest in the capital good, thereby earning a profit equal to the net own-rate of return $r(t) / p(t)$, or invest in gold, thereby earning a profit equal to the net own-rate of return $R_{G}(t) / p_{G}(t)$. We assume that capital and gold markets are in competitive equilibrium at any point in time, so the two options must yield equal returns, i.e.,

$$
\frac{r(t)}{p(t)}=\frac{R_{G}(t)}{p_{G}(t)} .
$$

This equation enables us to determine the choice between owning gold and physical wealth. Daily life experience tells us that this assumption is made under many strict conditions. For instance, we neglect any transaction costs and any time needed for buying and selling goods. Equation (5) also implies perfect information.

\section{Behavior of consumers}

Unlike the optimal growth theory, in which utility defined over future consumption streams is used, we do not explicitly specify how consumers discount future utility resulting from consuming goods and services. This study uses the approach to consumers' behavior proposed by Zhang (1993). Extensive explanations and many examples applying this approach are provided by Zhang $(2005,2006)$. Let $\pi(t)$ and $\vec{k}(t)$, respectively, stand for the inflation rate and the per capita (physical) wealth. We have

$$
\pi(t)=\frac{\dot{p}(t)}{p(t)} .
$$


Zhang: Money and price dynamics under the gold standard in the neoclassical theory...

Let $\hat{g}(t)$ stand for the amount of gold owned by the representative household. Current income per capita is given by

$$
y(t)=r(t) p(t) \bar{k}(t)+R_{G}(t) \hat{g}(t)+w(t)-\pi(t) m(t),
$$

where $r p \bar{k}$ is the interest payment, $R_{G} \hat{g}$ is the rent revenue from owning gold, $w$ is the wage payment, and $\pi m$ is the cost of holding money. Let $a(t)$ stand for the total value of assets that the representative household owns. We have

$$
a(t)=p(t) \bar{k}(t)+p_{G}(t) \hat{g}(t)+m(t) .
$$

The total value of wealth that the representative household can sell to purchase goods and to save is equal to $a(t)$. Here, we assume that selling and buying wealth can be conducted instantaneously without any transaction cost. Disposable income is the sum of current income and total value

$$
\hat{y}(t)=y(t)+a(t)
$$

At each point in time, the household distributes the total available budget between money balances, $m(t)$, the amount of gold for decoration/ornament, $\bar{g}(t)$, saving, $s(t)$, and consumption of goods, $c(t)$. The budget constraint is given by

$$
(1+r(t)) m(t)+R_{G}(t) \bar{g}(t)+p(t) c(t)+s(t)=\hat{y}(t) .
$$

From (10), (8) and (9), we have

$$
(\pi(t)+r(t)) m(t)+R_{G}(t) \bar{g}(t)+p(t) c(t)+s(t)=\bar{y}(t),
$$

where

$$
\bar{y}(t) \equiv(1+r(t)) p(t) \bar{k}(t)+R_{G}(t) \hat{g}(t)+w(t)+p_{G}(t) \hat{g}(t) .
$$

In Zhang's approach, the utility function is dependent on saving from disposable income, consumption, gold holdings, and money holdings (Zhang, 
2006). In this model, the representative household has four variables to decide on: $s(t), c(t), m(t)$, and $\bar{g}(t)$. The consumer's utility function is specified as follows:

$$
U(t)=c^{\xi_{0}}(t) \bar{g}^{\gamma_{0}}(t)\left(\frac{m(t)}{p(t)}\right)^{\varepsilon_{0}}\left(\frac{s(t)}{p(t)}\right)^{\lambda_{0}}, \xi_{0}, \varepsilon_{0}, \gamma_{0}, \lambda_{0}>0,
$$

in which $\xi_{0}, \gamma_{0}, \varepsilon_{0}$, and $\lambda_{0}$ are the elasticities of utility with respect to industrial goods, gold, real money holdings, and real savings. We call $\xi_{0}, \gamma_{0}, \varepsilon_{0}$, and $\lambda_{0}$ propensities to consume industrial goods, to use gold, to hold real money, and to save, respectively. Maximizing (12) subject to (11) yields

$$
\begin{aligned}
p(t) c(t) & =\xi \bar{y}(t), \\
R_{G}(t) \bar{g}(t) & =\gamma \bar{y}(t), \\
(\pi(t)+r(t)) m(t) & =\varepsilon \bar{y}(t), \\
s(t) & =\lambda \bar{y}(t),
\end{aligned}
$$

where

$$
\xi \equiv \rho \xi_{0}, \gamma \equiv \rho \gamma_{0}, \varepsilon \equiv \rho \varepsilon_{0}, \lambda \equiv \rho \lambda_{0}, \rho=\frac{1}{\xi_{0}+\varepsilon_{0}+\gamma_{0}+\lambda_{0}} .
$$

\section{E. Closing the model}

\section{Wealth accumulation}

According to the definitions of $s(t)$, the change in the representative household total wealth is given by

$$
\dot{a}(t)=s(t)-a(t) .
$$

This equation simply states that the change in wealth is equal to saving minus dissaving. 
Zhang: Money and price dynamics under the gold standard in the neoclassical theory...

\section{Gold market clearing}

The amount of gold owned by the population is equal to the amount of gold used by the population

$$
\bar{g}(t) N=\hat{g}(t) N
$$

3. Gold being fully used

The gold is owned by the government and the population

$$
\hat{g}(t) N+G_{b}(t)=G \text {. }
$$

4. Equilibrium in the money market

The demand for money equals the supply of money

$$
m(t) N=M^{s}(t) .
$$

\section{Physical capital accumulation}

The accumulation of physical capital is described by

$$
\dot{K}(t)=F(t)-c(t) N-\delta_{k} K(t) .
$$

This is simply an accounting relation.

\section{Physical capital market clearing}

The total physical capital is owned by the households

$$
\bar{k}(t) N=K(t) .
$$

We have thus built the dynamic model. It should be noted that the model is general in the sense that the Solow model can be considered as a special case of our model. Moreover, as our model is based on some well-known mathematical models and includes some features that no other single theoretical model explains, we should be able to explain some interactions that other formal models fail to explain. We now examine the dynamics of the model. 


\section{The dynamics and its properties}

The economic system contains many variables. These variables are nonlinearly related. For illustration, the rest of the study simulates the model. In order to simulate the model computationally, we provide a programming procedure so that anyone can easily follow the motion of the economic system with any set of parameters and initial conditions. In the Appendix, we show that the dynamics of the economy can be expressed by three differential equations.

Lemma: The dynamics of the economy is governed by the following threedimensional system of differential equations:

$$
\begin{aligned}
\dot{p}(t) & =\Omega_{p}(p(t), \bar{k}(t), a(t)), \\
\dot{\bar{k}}(t) & =\Omega_{\bar{k}}(p(t), \bar{k}(t), a(t)), \\
\dot{a}(t) & =\Omega_{a}(p(t), \bar{k}(t), a(t)),
\end{aligned}
$$

where $\Omega_{p}, \Omega_{\bar{k}}$, and $\Omega_{a}$ are functions of $p(t), \bar{k}(t)$, and $a(t)$.

Proof: see the Appendix.

Moreover, all the other variables are determined as functions of $p(t), \bar{k}(t)$, and $a(t)$ by the following procedure: $r(t)$ and $w(t)$ by (A2) $\rightarrow \bar{y}(t)$ by (A7) $\rightarrow \pi(t)$ by (A14) $\rightarrow m(t)$ by (A12) $\rightarrow p_{G}(t)$ by (A10) $\rightarrow R_{G}(t)$ by (A5) $\rightarrow c(t), s(t)$, and $\bar{g}(t)$ by (13) $\rightarrow K(t)$ by (19) $\rightarrow F(t)$ by (1) $\rightarrow \hat{g}(t)=$ $\hat{g}(t) \rightarrow M^{s}(t)=m(t) N \rightarrow G_{b}(t)$ by (A3).

The system of differential equations (20) has three variables: $p(t), \bar{k}(t)$, and $a(t)$. As shown in the Appendix, the expressions are complicated, so it is difficult to explicitly derive economic implications from the three equations. For illustration, we simulate the model to illustrate the behavior of the system. In the remainder of this study, we specify the parameters in Table 1.

The propensity to save is 0.8 and the propensity to consume is 0.1 . As the propensity to save implies that the proportion of disposable income used for saving and disposable income is the sum of the value of wealth and current income. The assumed value of $\lambda_{0}$ simply implies that 80 percent of household disposable income is for saving. Total factor productivity is $A=1$. The 
Zhang: Money and price dynamics under the gold standard in the neoclassical theory...

amount of gold is 1 and the population is 10 . The propensity to hold money is 0.01 and the propensity to use gold is 0.001 . In regard to the preference parameters, what are important in our study are their relative values. The gold backing ratio is 0.008 . The depreciation rate of physical capital is 0.05 . To follow the motion of the system, we specify the initial conditions $p(0)=$ $2.6, \bar{k}(0)=11, a(0)=35$.

Table 1. Parameterization of the model

\begin{tabular}{cc}
\hline Parameter & Value \\
\hline$\alpha$ & 0.35 \\
$A$ & 1 \\
$N$ & 10 \\
$G$ & 1 \\
$\lambda_{0}$ & 0.8 \\
$\xi_{0}$ & 0.1 \\
$\varepsilon_{0}$ & 0.01 \\
$\gamma_{0}$ & 0.001 \\
$\theta$ & 0.008 \\
$\delta_{k}$ & 0.06 \\
\hline
\end{tabular}

Source: own elaboration.

The simulation results are plotted in Figure 1. We simulate the model in a short period of time. The reason is that the system is unstable, as explained later. It does not have a stable equilibrium point. Due to the initial conditions, total output and the capital stock are increased. As the wage rates fall, both men and women work longer hours. Their leisure hours are reduced. The economy's wealth and output are increased in association with rising labor force. Nevertheless, both consumption level and wealth per household are reduced.

The simulation confirms that the system has the following equilibrium point. We list the equilibrium values of the variables in Table 2.

We calculate the three eigenvalues: $0.11+0.64 i, 0.11-0.64 i,-0.64$.

As two of the three eigenvalues' real parts are positive, the equilibrium point is unstable. Thus, the system tends to be away from its equilibrium 
point if it is not located at it. ${ }^{2}$ If the system is unstable, comparative static analysis provides little insight into its behavior. In our model, long-run price stability is not guaranteed. ${ }^{3}$ If a system is not stable, it is hard to predict the long-term consequences of any change in the parameters. As our model explicitly shows the dynamic path of the economic system, we can conduct comparative dynamic analysis effectively at least during a short period of time.

Figure 1. Motion of the Economic System
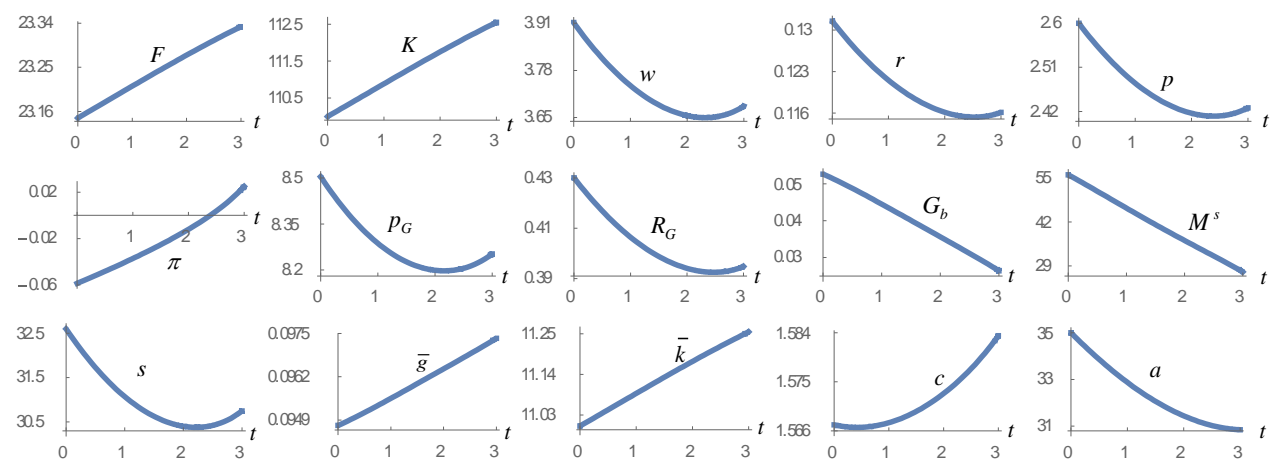

Source: own simulations.

2 Many of the monetary growth models tend to have unstable equilibrium points. There are different reasons for instabilities. For instance, Barro observed (1979, p. 33): “A dependence of the expected inflation rate, $\pi$, on the time path of $\mathrm{P}$ or other variables leads to deeper stability questions of the sort discussed by Cagan (1956) and Goldman (1972) under adaptive expectations and by Sargent and Wallace (1973) in a deterministic, rational expectations setting."

3 It should be noted that Bohanon (1985, p. 16-17) also discusses issues related to instabilities of the economic system under a gold standard as follows: "Many economists have concluded that under a gold standard prices are inexorably driven back to some fixed level, and in the long run the exchange value of all goods and the value of all dollar contracts is guaranteed (Lehrman, 1981 and Wanniski, 1981). [...] Although there are restrictive conditions under which long-run price stability may occur, our analysis indicates that short-run or long-run price stability is not the natural state of affairs under a gold standard." 
Zhang: Money and price dynamics under the gold standard in the neoclassical theory...

Table 2. Equilibrium values

\begin{tabular}{cc}
\hline Variable & Value \\
\hline $\bar{g}$ & 0.097 \\
$G_{b}$ & 0.029 \\
$m$ & 3.42 \\
$M^{s}$ & 34.18 \\
$K$ & 117.07 \\
$r$ & 0.13 \\
$w$ & 4.18 \\
$p$ & 2.72 \\
$R_{G}$ & 0.47 \\
$p_{G}$ & 9.57 \\
$F$ & 23.66 \\
$\bar{k}$ & 11.71 \\
$c$ & 1.66 \\
$a$ & 36.18 \\
\hline
\end{tabular}

Source: own elaboration.

\section{Comparative dynamic analysis through simulations}

We simulated the motion of the economy under (21). We now examine how the economic system reacts to some exogenous change. As the lemma gives the computational procedure to calibrate the motion of all the variables, it is straightforward to examine the effects of a change in any parameter on transitory processes as well stationary states of all the variables. It should be noted that we do not describe the changes in the equilibrium point, as the system is unstable, and it provides little information about the motion of the dynamic system in the long term. Let $\bar{\Delta} x(t)$ stand for the percentage rate of change of the variable $x(t)$, due to changes in the parameter value.

\section{A. $A$ rise in the gold backing ratio}

As in Barro (1979), we consider that a reduction in paper gold can be modelled by a rise in $\theta$. We specify the increase as follows: $\theta: 0.008 \Rightarrow 0.009$. This 
implies that the money stock is reduced for a fixed amount of gold backing. The simulation results are plotted in Figure 2. The variables whose values are not affected by the parameter change are not included in Figure 2. The gold price and gold-use cost fall during the period of simulation. The government holds more gold and the household holds less. As in Barro (1979), a change in $\theta$ has no effect on the equilibrium values of the price level and money stock. In our approach, changes in $\theta$ only affect the gold distribution, gold price and gold-use cost. The reason for this difference is that we take account of households' gold holding.

Figure 2. A Rise in the Gold Backing Ratio
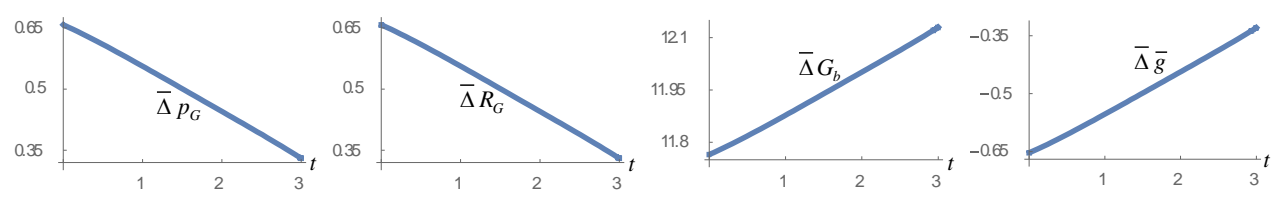

Source: own simulations.

\section{B. Fall in the propensity to hold paper money}

We are now concerned with how the propensity to hold paper money affects economic growth. We reduce the propensity to hold paper money as follows: $\varepsilon_{0}: 0.01 \Rightarrow 0.008$. The simulation results are plotted in Figure 3 . In Figure 3, we use $\Delta \pi(t)$. We use this symbol as the path of the inflation rate passes the zero point. As the household propensity to hold money falls, both the inflation rate and rate of interest are reduced. These changes tend to reduce the costs of holding money. The net result of cost reduction and falling propensity to hold paper money increases money supply. The capital stock and output fall initially and then rise. The wage rate, price of the good, gold-use cost and gold price are all reduced. The government holds more gold and the household owns less gold. The consumption level rises initially and then falls. Total wealth falls.

We see that our simulation results imply that it is possible to observe the rate of interest and the inflation rate change in the same direction. It should 
Zhang: Money and price dynamics under the gold standard in the neoclassical theory...

be noted that the so-called Fisher effect, which is based on $i(t)=r(t)+\pi(t)$, where $i(t)$ is the nominal interest rate, says that if $\pi(t)$ rises by one then $i(t)$ must also rise by one. The Mundell-Tobin effect implies that $i(t)$ does not rise 1:1 with $\pi(t)$. We see that our results do not support the Fisher effect and agrees with the Mundell-Tobin effect. As our modelling approach is different from the Tobin model (Tobin, 1965; Zhang, 2009), we will not examine this issue in detail.

Figure 3. A Fall in the Propensity to Hold Paper Mone

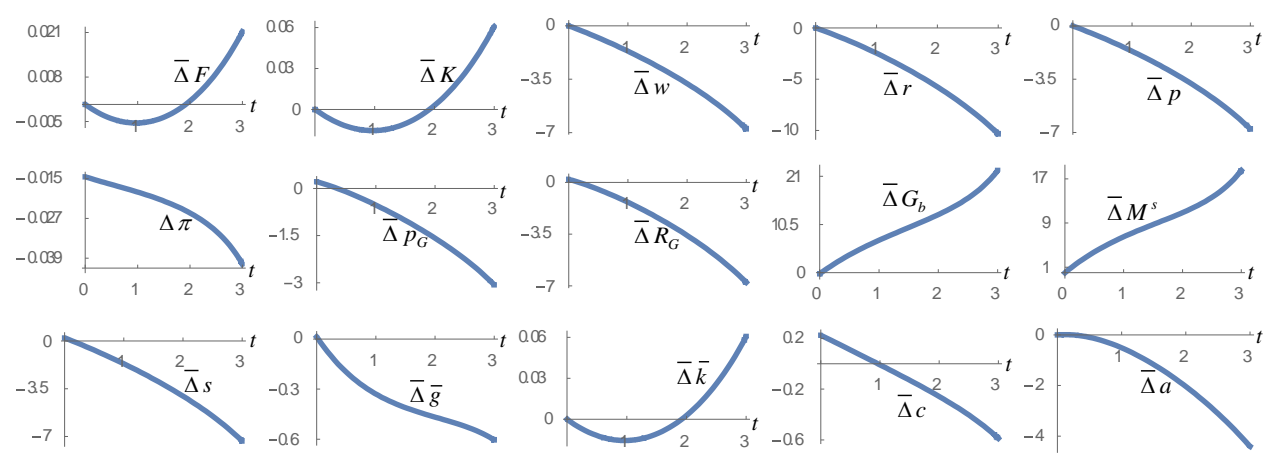

Source: own simulations.

\section{A rise in the household propensity to use gold}

We now study the effects of the following rise in the propensity to use gold $\gamma_{0}: 0.001 \Rightarrow 0.0015$. The simulation results are plotted in Figure 4. As the household propensity to use gold is increased, the representative household tends to hold more gold in association with increasing gold price and golduse costs. The government holds less gold and the economy has less physical wealth. It should be noted that, as in our approach the total gold is fixed, an enhanced preference for gold makes the household hold more gold. The money supply is reduced. Capital stock and output fall. The wage rate, price of the good, gold-use cost and gold price are all increased. The inflation rate is slightly increased. The consumption level rises. Total wealth rises. 
Figure 4. A Rise in the Household's Propensity to Use Gold
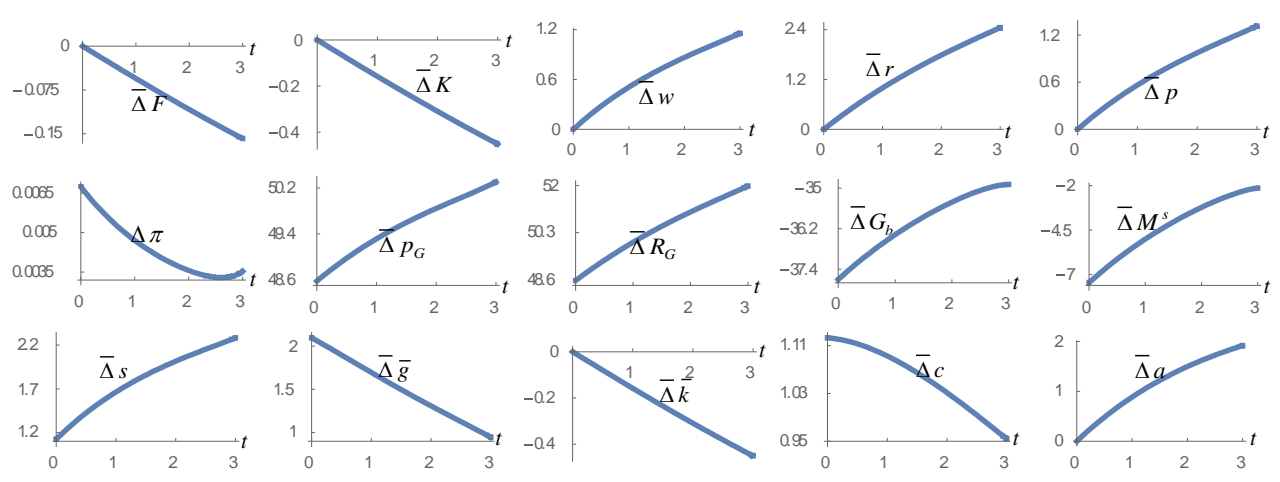

Source: own simulations.

\section{A rise in the total factor productivity}

We are now concerned with how total factor productivity affects economic growth. We now increase total factor productivity as follows: $A$ : $1 \Rightarrow$ 1.1. The simulation results are plotted in Figure 5. As productivity is enhanced, the output level, national physical capital and wage rate are increased during the simulation period. The gold-use cost is increased, and the gold price is reduced. The inflation rate is reduced. The rate of interest is increased, and the price level is reduced. The household holds less gold and the government holds more gold. The money supply is expanded. The household consumes more and holds more total wealth.

\section{E. The impact of the propensity to save}

We now examine what will happen when the propensity to save is increased as follows: $\lambda_{0}: 0.8 \Rightarrow 0.81$. The simulation results are plotted in Figure 6. As the propensity to save is enhanced, the output level and physical capital are both increased. Both the wage rate and the rate of interest are reduced. It should be noted that, in the standard neoclassical growth model without gold, the change in directions of the wage rate and the rate of interest are the opposite when the propensity to save is changed. The gold-use cost and 
Zhang: Money and price dynamics under the gold standard in the neoclassical theory...

the gold price are decreased. The inflation rate is lowered. The household owns less gold and the government holds more gold. The money supply is expanded. The household consumes less and holds more total wealth.

Figure 5. A Rise in Total Factor Productivity
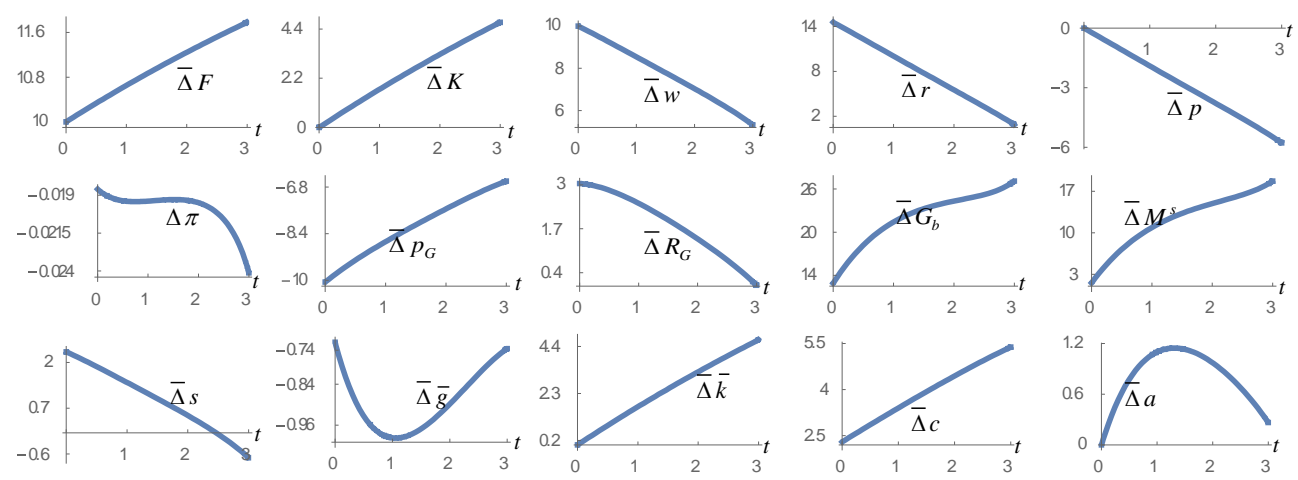

Source: own simulations.

Figure 6. Impact of the Propensity to Save
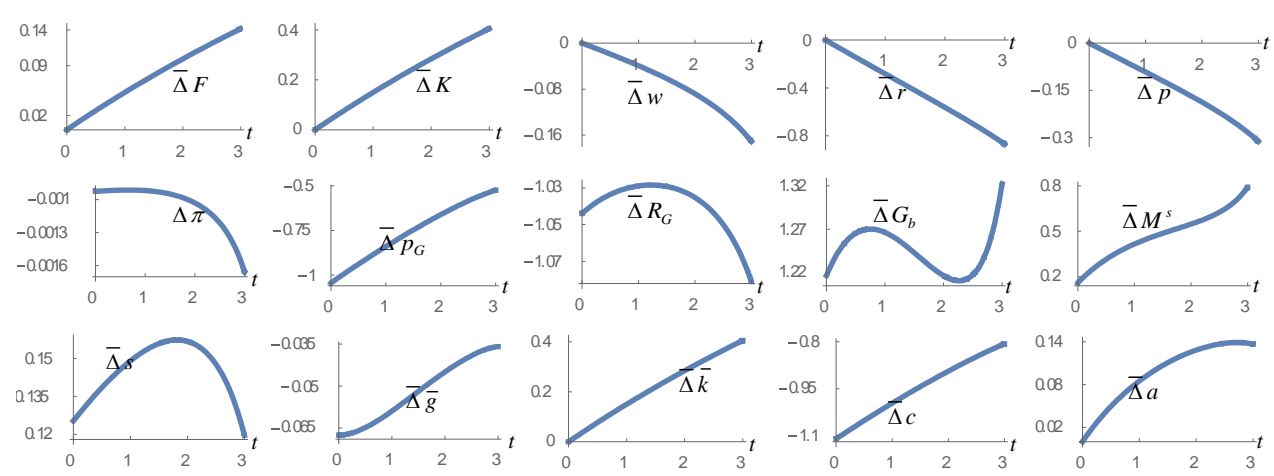

Source: own simulations.

\section{F. $A$ rise the output elasticity of labor}

We now examine what will happen when the output elasticity of labor is increased as follows: $\beta$ : $0.65 \Rightarrow 0.66$. The simulation results are plotted in 
Figure 7. The change in the parameter means that the share of labor cost in total cost is increased. It also means that the share of physical capital cost in total cost is reduced. The output level and physical capital are both reduced. Both the wage rate and the rate of interest are reduced initially and then increased. The total wealth is reduced initially and then increased. The gold-use cost is reduced initially and then enhanced. The gold price is increased. The inflation rate is enhanced. The household owns more gold and the government holds less gold. The money supply is reduced. The household consumes less. The household initially owns less total wealth and then more.

Figure 7. A Rise in the Output Elasticity of Labor

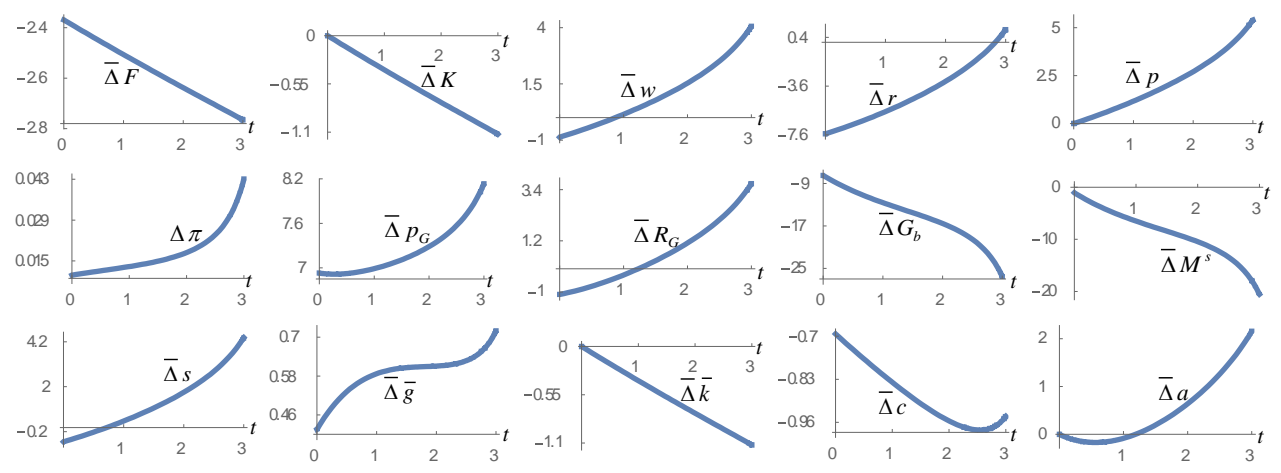

Source: own simulations.

\section{Concluding Remarks}

This paper introduced money and gold into the Solow growth model. The study proposed a dynamic interdependence between gold distribution between monetary and non-monetary uses of gold, the gold price, money demand and supply, inflation, physical capital accumulation, wealth accumulation, and production. That way, the model determines money and price dynamics under the gold standard in the one-sector neoclassical growth model. The model was built upon a few approaches in the literature on the theory of economic growth. The production sector is based on the Solow model. The gold standard and price dynamics are based on Barro (1979). 
Zhang: Money and price dynamics under the gold standard in the neoclassical theory...

Household behavior is based on Zhang's approach, which in turn is based on the traditional MIU model. The model integrated the ideas of these approaches within a compact framework. Through simulations, we show that the economic system has a unique unstable steady state. The study conducts comparative dynamic analysis regarding changes in some parameters.

As this model is built on many strict assumptions, we may generalize it and extend it by relaxing some of these. For instance, we may generalize the model by using more general functional forms for production and utility. It is also possible to extend the model by taking account of household heterogeneity. It is also important to generalize the model within a framework of heterogeneous sectors. This study does not take account of risks in different markets. Gold is often kept as a way of diversifying risks. A further understanding of dynamics in the gold market requires introduction of speculation and volatility. Although this study treats the gold supply as fixed, the supply of gold may also be derived from profit optimization in the gold mining industry in a framework where gold ore is exhaustible (e.g., Bordo \& Ellson, 1985 and Dowd \& Sampson, 1993).

\section{Appendix: Proof of Lemma}

We now show that the dynamics can be expressed by a three-dimensional system of differential equations. From (2) and (19), we obtain

$$
z \equiv \frac{r+\delta_{k}}{w}=\frac{\widetilde{\alpha}}{\bar{k}}
$$

where $\widetilde{\alpha} \equiv \alpha / \beta$. From (2) and (3), we have

$$
r(\bar{k}, p)=r_{0} p z^{\beta}-\delta_{k}, w(\bar{k}, p)=\frac{w_{0} p}{z^{\alpha}},
$$

where

$$
r_{0} \equiv \frac{\alpha A}{\widetilde{\alpha}^{\beta}}, w_{0} \equiv \beta A \widetilde{\alpha}^{\alpha} .
$$

From the definition of $\bar{y}$ and (A2), we have

$$
\bar{y}=(1+r) p \bar{k}+\left(R_{G}+p_{G}\right) \hat{g}+w .
$$


Substituting (5) in (A3),

$$
\bar{y}=(1+r) p \bar{k}+\left(\frac{r}{p}+1\right) p_{G} \hat{g}+w .
$$

From $R_{G} \bar{g}=\gamma \bar{y}$ in (13) and (A4), we get

$$
\bar{y}(\bar{k}, p)=(1+r) p \hat{p} \bar{k}+\hat{p} w,
$$

where we also use (15) and

$$
\hat{p}(\bar{k}, p) \equiv\left(1-\gamma-\frac{\gamma p}{r}\right)^{-1}
$$

From (3) and (16),

$$
\theta m N=p_{G} G-p_{G} \hat{g} N
$$

where we also use (17). Substituting $R_{G} \bar{g}=\gamma \bar{y}$ in (13) in (A6),

$$
\theta m N=p_{G} G-\frac{p \gamma \bar{y} N}{r} .
$$

Substituting $(\pi+r) m=\varepsilon \bar{y}$ in (13) in (A7),

$$
p_{G}=\left(\frac{\theta \varepsilon}{\pi+r}+\frac{\gamma p}{r}\right) \frac{N \bar{y}}{G} .
$$

From $R_{G} \bar{g}=\gamma \bar{y}$ and (5), we have

$$
\frac{p_{G} \bar{g} r}{p}=\gamma \bar{y}
$$

From (A8) and (A9), we have

$$
\bar{g}=\left(\frac{\theta \varepsilon}{\pi+r}+\frac{\gamma p}{r}\right)^{-1} \frac{\gamma p G}{r N} .
$$


Zhang: Money and price dynamics under the gold standard in the neoclassical theory...

From (A9) and (8), we have

$$
a=p \bar{k}+\frac{\gamma p \bar{y}}{r}+m
$$

Substituting $(\pi+r) m=\varepsilon \bar{y}$ in (13) in (A11),

$$
a=p \bar{k}+\left(\frac{\gamma p}{r}+\frac{\varepsilon}{\pi+r}\right) \bar{y} .
$$

Solving for $\pi$ from (A12),

$$
\pi(\bar{k}, p, a)=\left(\frac{a}{\bar{y}}-\frac{p \bar{k}}{\bar{y}}-\frac{\gamma p}{r}\right)^{-1} \varepsilon-r .
$$

From (6) and (A13), we have

$$
\dot{p}=\Omega_{p}(\bar{k}, p, a) \equiv p \pi(\bar{k}, p, a) .
$$

By $\bar{k} N=K$ and (18), we have

$$
\dot{\bar{k}}=\Omega_{\bar{k}}(\bar{k}, p, a) \equiv A \bar{k}^{\alpha}-\frac{\xi \bar{y}}{p}-\delta_{k} \bar{k},
$$

where we also use (1) and (13). From (14) and (13), we get

$$
\dot{a}=\Omega_{a}(\bar{k}, p, a) \equiv \lambda \bar{y}-a .
$$

From (A15)-(A17), we obtain the motion of the three variables $\bar{k}, p$, and $a$. The following procedure shows how to express all the other variables as functions of $\bar{k}, p$, and $a: z$ by (A1) $\rightarrow r$ and $w$ by (A2) $\rightarrow \bar{y}$ by (A7) $\rightarrow \pi$ by (A14) $\rightarrow m$ by (A12) $\rightarrow p_{G}$ by (A10) $\rightarrow R_{G}$ by (A5) $\rightarrow c, s$, and $\bar{g}$ by (13) $\rightarrow K$ by (19) $\rightarrow F$ by (1) $\rightarrow \hat{g}=\bar{g} \rightarrow M^{d}=m N \rightarrow G_{b}$ by (A3). 


\section{References}

Azariadis, Costas (1993). Intertemporal Macroeconomics. Oxford: Blackwell.

Barro, Robert J. (1979). "Money and the Price Level under the Gold Standard”, Economic Journal, Vol. 89, No. 353, pp. 13-33.

Barro, Robert J. \& Sala-i-Martin, Xavier (1995). Economic Growth. New York: McGraw-Hill Inc.

Bohanon, Cecil E.; Lynch, Gerald J. \& van Cott, T. Norman (1985). “A Supply and Demand Exposition of the Operation of a Gold Standard in a Closed Economy", Journal of Economic Education, Vol. 16, No. 1, pp. 16-26.

Bordo, Michael David \& Ellson, Richard Wayne (1985). "A Model of the Classical Gold Standard with Depletion”, Journal of Monetary Economic, Vol. 16, No. 1, pp. 109-120.

Burmeister, Edward \& Dobell, Rodney (1995). Mathematical Theories of Economic Growth. London: MacMillan.

Cagan, Phillip (1956). “The Monetary Dynamics of Hyperinflation”. In Friedman, M. (Ed.), Studies in the Quantity Theory of Money (pp. 25117). Chicago: University of Chicago Press.

Chappell, David \& Dowd, Kevin (1997). "A Simple Model of the Gold Standard", Journal of Money, Credit and Banking, Vol. 29. No. 1, pp. 94-105.

Dempster N. (2009, July). "Gold as a Tactical Inflation Hedge and Long-term Strategic Asset", World Gold Council. Retrieved from: http://www.gold.org/download/rs_archive/AssetAllocation_ Inflation_July09.pdf.

Dowd, Kevis \& Sampson, Anthony A. (1993). "A New Model of the Gold Standard”, The Canadian Journal of Economics, Vol. 26, No. 2, pp. 380391. 
Zhang: Money and price dynamics under the gold standard in the neoclassical theory...

Dubey, Pradeep; Geanakoplos, John \& Shubik, Martin (2003). "Is Gold an Efficient Store of Value", Economic Theory, Vol. 21, No. 4, pp. 767-782.

Goldman, Steven M. (1972). "Hyperinflation and the Rate of Growth in the Money Supply”, Journal of Economic Theory, Vol. 5, No. 2, pp. 250-257.

Keynes, John Maynard et al. (1943). "Proposals by British Experts for an International Clearing Union", In Proceedings and Documents of the United Nations Monetary and Financial Conference vol. 2. Washington: U.S. Government Printing Office, 1948.

Lehrman, Lewis (1981, 30 July). The Case for a Gold Standard. Wall Street Journal.

Mundell, R. A. (1968). International Economics. New York: Macmillan.

Patinkin, Don (1965). Money, Interest, and Prices: An Integration of Monetary and Value Theory ( $2^{\text {nd }}$ Ed.). New York: Harper \& Row.

Ranson, David (2005). "Inflation Protection: Why Gold Works Better Than Other Linkers", World Gold Council. Retrieved from: http://www.gold.org/download/rs_archive/inflation_linkers.pdf._

Ricardo, David (1911). The Principles of Political Economy and Taxation. London: J. M. Dent \& Sons. (Original work published 1821).

Sargent, Thomas J. \& Wallace, Neil (1973). "The Stability of Models of Money and Growth with Perfect Foresight", Econometrica, Vol. 41, No. 6, pp. 1043-1048.

Seemuang, Ananya \& Rompreert, Suppanunta (2013). "Gold Value Movement and Macroeconomics", Journal of Business and Economics, Vol. 4, No. 8, pp. 752-60.

Sidrauski, Miguel (1967). "Rational Choice and Patterns of Growth in a Monetary Economy”, American Economic Review, Vol. 57, No. 2, pp. 534-544.

Solow, Robert (1956). "A Contribution to the Theory of Growth", The Quarterly Journal of Economics, Vol. 70, No. 1, pp. 65-94. 
Thomas, H. (2015, 5 june). Don't Expect Peak Gold Prospects to Mean New Price Heights. Wall Street Journal.

Tobin, James (1965). "Money and Economic Growth", Econometrica, Vol. 33, No. 4, pp. 671-684.

Triffin, Robert (1960). Gold and the Dollar Crisis. New Haven: Yale University Press.

Wanniski, Jude (1981, 7 December). Supply-Side Case for a Gold Standard. Business Week.

Zhang, Wei-Bin (1993). "Woman's Labor Participation and Economic Growth - Creativity, Knowledge Utilization and Family Preference", Economics Letters, Vol. 42, No. 1, pp. 105-110.

Zhang, Wei-Bin (2005). Economic Growth Theory. Hampshire: Ashgate.

ZhANG, Wei-Bin (2006). Growth with Income and Wealth Distribution. London: Macmillan.

Zhang, Wei-Bin (2009). "A Small Open Interregional Monetary Economic Growth with the MIU Approach", Annals of the Alexandru Ioan Cuza University of Iasi, Vol. 56, pp. 210-234. 